\title{
Everolimus in Metastatic Renal Cell Carcinoma: Preliminary Experience from Chang Gung Memorial Hospital
}

\author{
Wen-Kuan Huang, MD; Chuang-Chi Liaw, MD; See-Tong Pang ${ }^{1}$, MD, PhD; \\ Cheng-Keng Chuang ${ }^{1}$, MD; Yang-Jen Chiang ${ }^{1}$, MD; Chun-Te $\mathrm{Wu}^{1}$, MD; \\ Ying-Hsu Chang ${ }^{1}$, MD; Hung-Ming Wang, MD; Yung-Chang Lin, MD; \\ Jia-Juan Hsieh, MS; Li-Ying Ou, SC; Shih-I Tsai, SC; Chih-Hsun Yang², MD; \\ Cheng-Ta Yang ${ }^{3}$, MD; John Wen-Cheng Chang, MD
}

Background: Everolimus has been approved for second-line treatment of patients with metastatic renal cell carcinoma (mRCC) after failure of sorafenib or sunitinib. The purpose of this retrospective study was to assess the efficacy and safety of everolimus in Taiwanese patients with mRCC.

Methods: Between March 2009 and August 2011, 24 mRCC patients treated with everolimus were analyzed. Prior to everolimus, each patient had received therapy with at least one vascular endothelial growth factor receptor-tyrosine kinase inhibitor. Progression-free survival (PFS) and overall survival (OS) were estimated according to the Kaplan-Meier method.

Results: $\quad$ Fifteen patients $(62.5 \%)$ achieved stable disease. The median PFS was 7.1 months (95\% confidence interval, 3.6-10.5 months). The median OS was 20.7 months (95\% confidence interval, 5.0-36.4 months). The most frequent non-hematologic adverse events with everolimus were mucositis, rash, epistaxis and pneumonitis.

Conclusions: Everolimus is an effective second-line treatment for Taiwanese patients with $\mathrm{mRCC}$. The toxicity is tolerable and manageable.

(Chang Gung Med J 2012;35:402-7)

Key words: everolimus, mammalian target of rapamycin (mTOR) inhibitor, renal cell cancer

$\mathrm{I}_{1}^{\mathrm{n}}$ Taiwan, renal cell carcinoma (RCC) accounts for $1 \%$ of all cancer cases. Approximately, 800 patients are newly diagnosed with RCC annually. The incidence rate per 100,000 person-years was $3.1 \%$ in $2008 .^{(1)}$ RCCs arise from the proximal renal tubules, and approximately $85 \%$ are the clear cell type. When patients with RCC present with localized disease, surgical resection remains the only known curative treatment. Unfortunately, one-third of the patients with resectable localized disease will eventually relapse. ${ }^{(2)}$ Furthermore, $20 \%-30 \%$ of patients have metastatic disease at diagnosis, and the 5-year survival for patients with metastatic disease is less than $10 \%$.

From the Division of Hematology-Oncology; 'Division of Urology; ${ }^{2}$ Department of Dermatology; ${ }^{3}$ Division of Thoracic Medicine, Chang Gung Memorial Hospital at Linkou, Chang Gung University College of Medicine, Taoyuan, Taiwan.

Received: Nov. 16, 2011; Accepted: Feb. 20, 2012

Correspondence to: Dr. John Wen-Cheng Chang, Division of Hematology-Oncology, Chang Gung Memorial Hospital at Linkou. 5, Fusing St., Gueishan Township, Taoyuan County 333, Taiwan (R.O.C.) Tel: 886-3-3281200 ext. 8825;

Fax: 886-3-3281200 ext. 2362; E-mail: wen1902@hotmail.com 
Cytokines (i.e., interferon- $\alpha$ and interleukin 2) were the mainstay of treatment for advanced RCC before the development of targeted therapies. In recent years, an understanding of the pathogenesis of $\mathrm{RCC}$ has aided in elucidating the critical role of the von Hippel-Lindau (VHL) tumor suppressor gene. Several agents that target the vascular endothelial vascular growth factor (VEGF) pathway and the mammalian target of rapamycin (mTOR) pathway have proven significantly effective against this disease. . $^{(3,4)}$

Everolimus (Afinitor; Novartis, U.S.A.), an orally administered mTOR inhibitor, has been studied as an immunosuppressant for solid organ transplantation. ${ }^{(5)}$ In a Phase I trial for the safety evaluation of the daily dosing of everolimus (up to $10 \mathrm{mg}$ ), one patient with RCC was found to have a confirmed partial response. ${ }^{(6)}$ A single-arm phase II trial that enrolled 41 RCC patients reported a median progression-free survival (PFS) and a median overall survival (OS) of 11.2 and 22.1 months, respectively, and $70 \%$ of the patients achieved either a tumor response or disease stabilization for 6 months or more. ${ }^{(7)}$ The pivotal Phase III trial, the Renal Cell cancer treatment with Oral RAD001 given Daily (RECORD)-1 trial, randomized 410 patients with advanced RCC to either everolimus $10 \mathrm{mg}$ daily or placebo groups. ${ }^{(8)}$ All patients exhibited a clear cell histology type that had progressed within 6 months of therapy with the VEGF receptor tyrosine kinase inhibitors (VEGFRTKI) sunitinib, sorafenib, or both. The median PFS in the everolimus group was significantly prolonged compared with that in the placebo group (4.9 versus 1.9 months; hazard ratio [HR] $0.30, p<0.001)$. The lack of a significant difference in the median OS between the everolimus and placebo groups in the final survival analysis could be attributed to the effects of crossover. The overall objective responses (ie, complete and partial responses) were quite low (1\% and $0 \%$ with everolimus and placebo, respectively), while disease stabilization was more common (66\% and 32\% with everolimus and placebo, respectively). Everolimus is considered the standard treatment for patients with advanced RCC after failure of sorafenib or sunitinib. However, there is still limited experience with regard to the efficacy of everolimus in the treatment of RCC in Taiwan. Here we present our experience with everolimus in metastatic RCC (mRCC) at Chang Gung Memorial
Hospital in Taiwan.

\section{METHODS}

The study was reviewed and approved by the Institutional Review Board of Chang Gung Memorial Hospital. (IRB No.: 100-3178B). Twentyfour patients with pathologically diagnosed RCC who were treated with everolimus after disease progression or intolerability with at least one VEGFRTKI between March 2009 and August 2011 were enrolled. Patients were required to have adequate bone marrow function (absolute neutrophil count $\geq 1.5 \times 10^{9} / \mathrm{L}$, hemoglobin $\geq 9 \mathrm{~g} / \mathrm{dL}$, platelet count $\geq 100 \times 10^{9} / \mathrm{L}$ ), hepatic function (serum total bilirubin $\leq 1.5 \mathrm{mg} / \mathrm{dL}$, aspartate transaminase or alanine transaminase $\leq 70 \mathrm{IU} / \mathrm{L}$ ), and renal function (serum creatinine $\leq 2 \mathrm{mg} / \mathrm{dL}$ ). Medical records, laboratory data, chest radiographs, bone scans and computed tomography scans were retrospectively reviewed. All enrolled patients received oral everolimus $10 \mathrm{mg}$ daily until disease progression or the occurrence of severe adverse events. Under the physician's judgment, the dose was either delayed or reduced to 5 $\mathrm{mg}$ /day if the patient had a severe adverse hematological event or other adverse event related to everolimus. Tumor response was assessed periodically according to the Response Evaluation Criteria in Solid Tumors criteria using computed tomography scans and bone scans. The clinical benefit rate was defined as the percentage of patients who had either a partial response or disease stabilization as the best response at any time during treatment. PFS was calculated from the start of everolimus treatment to the time of radiographic progression or death. Survival was calculated from the start of everolimus treatment to death or August 31, 2011, which was the cutoff date for follow-up. Patients who were alive on August 31, 2011 were censored from the analysis. Adverse events were estimated according to the National Cancer Institute Common Terminology Criteria for Adverse Events (version 4.0). Descriptive statistics and frequency counts were used to summarize the characteristics of the study population. The median PFS and OS were estimated using the Kaplan-Meier method. The statistical software SPSS 17.0 (SPSS, Inc., Chicago, IL, U.S.A.) was used for statistical analyses. 


\section{RESULTS}

\section{Patient and baseline characteristics}

A total of 24 patients with RCC were enrolled in the study. Of these, 20 patients $(83.4 \%)$ demonstrated clear cell histology, and 2 patients each $(8.3 \%)$ showed the papillary cell and chromophobe histology. Table 1 shows patient and baseline characteristics. Patients had a mean age of 54.8 years; $58.3 \%$ were males. All patients were relatively active with an Eastern Cooperative Oncology Group performance status of $\leq 2$. Fourteen patients $(59 \%)$ had a history of previous immunotherapy, and 13 patients (54.9\%) had been previously treated with sorafenib alone. After applying the Memorial Sloan-Kettering Cancer Center prognostic score, 17 patients $(70.9 \%)$ were determined to be at intermediate risk. All patients were treated with everolimus; the mean duration of treatment was 169 days.

\section{Efficacy}

As of the cutoff date, no complete or partial responses were noted. Fifteen patients $(62.5 \%)$ were determined to have stable disease, while disease progression was observed in 5 patients $(20.8 \%)$ (Table 2 ). Disease response could not be assessed in four patients, two who died shortly before image evaluation and two who had not yet undergone a CT scan before the cutoff date. There were 9 deaths $(37.5 \%)$ during the follow-up period. Kaplan-Meier analysis showed that the median PFS was 7.1 months $(95 \%$ confidence interval [CI], 3.6-10.5 months) (Fig. 1) and the median OS was 20.7 months (95\% CI, 5.0-36.4 months) (Fig. 2).

\section{Safety}

As summarized in Table 3, anemia (70.8\%), mucositis $(54.2 \%)$, and rash $(45.8 \%)$ were the most common adverse events among patients on everolimus therapy. Most adverse events were mild (Grade 1) to moderate (Grade 2) in intensity. Twenty-five percent of the patients showed increased alkaline phosphatase levels; of these, Grades 3/4 levels were reported in $8.3 \%$ of patients. Similarly, raised AST levels of Grades 1/2 were observed in $20.5 \%$ of patients. Metabolic profiles were available for some patients, and lipid disturbances such as hypercholesterolemia and hypertriglyceridemia of Grades $1 / 2$ were observed in $66.7 \%$ and $65 \%$ of
Table 1. Clinical Characteristics of Patients Receiving Everolimus $(\mathrm{N}=24)$

\begin{tabular}{|c|c|c|}
\hline Characteristic & Mean (range) & No. $(\%)$ \\
\hline Age: mean age, years (range) & $54.8(24-91)$ & \\
\hline \multicolumn{3}{|l|}{ Sex } \\
\hline Male & & $14(58.3 \%)$ \\
\hline Female & & $10(41.7 \%)$ \\
\hline \multicolumn{3}{|l|}{ Histology type } \\
\hline Clear cell carcinoma & & $20(83.4 \%)$ \\
\hline Papillary cell carcinoma & & $2(8.3 \%)$ \\
\hline Chromophobe type & & $2(8.3 \%)$ \\
\hline \multicolumn{3}{|l|}{ ECOG performance } \\
\hline 0 & & $5(20.8 \%)$ \\
\hline 1 & & $17(70.9 \%)$ \\
\hline 2 & & $2(8.3 \%)$ \\
\hline \multicolumn{3}{|l|}{ Previous nephrectomy } \\
\hline Yes & & $22(91.7 \%)$ \\
\hline No & & $2(8.3 \%)$ \\
\hline \multicolumn{3}{|l|}{ MSKCC risk factors } \\
\hline Favorable & & $6(25 \%)$ \\
\hline Intermediate & & $17(70.9 \%)$ \\
\hline Poor & & $1(4.1 \%)$ \\
\hline \multicolumn{3}{|l|}{ Prior VEGFR-TKI(s) } \\
\hline Sunitinib only & & $10(41 \%)$ \\
\hline Sorafenib only & & $13(54.9 \%)$ \\
\hline Both sunitinib and sorafenib & & $1(4.1 \%)$ \\
\hline \multicolumn{3}{|l|}{ Other previous systemic therapy } \\
\hline Chemotherapy & & $1(4.1 \%)$ \\
\hline Immunotherapy & & $14(59 \%)$ \\
\hline None & & $9(36.9 \%)$ \\
\hline \multicolumn{3}{|l|}{ Sites of metastases } \\
\hline Lymph nodes & & $8(33.8 \%)$ \\
\hline Lung & & $17(70.9 \%)$ \\
\hline Liver & & $8(33.8 \%)$ \\
\hline Bone & & $13(54.9 \%)$ \\
\hline Brain & & $1(4.1 \%)$ \\
\hline \multicolumn{3}{|l|}{ Number of disease sites } \\
\hline 1 & & $6(25 \%)$ \\
\hline 2 & & $9(37.5 \%)$ \\
\hline$\geq 3$ & & $9(37.5 \%)$ \\
\hline Treatment duration: mean days (range) & $169(2-603)$ & \\
\hline
\end{tabular}

Abbreviations: ECOG: Eastern Cooperative Oncology Group; MSKCC: Memorial Sloan-Kettering Cancer Center; VEGFR-TKI: vascular endothelial growth factor receptor- tyrosine kinase inhibitor. 
Table 2. Assessment of Response $(\mathrm{N}=24)$

\begin{tabular}{lc}
\hline Objective response & No. $(\%)$ \\
\hline Partial response & 0 \\
Stable disease & $15(62.5 \%)$ \\
Disease progression & $5(20.8 \%)$ \\
Disease could not be assessed & $4(16.7 \%)$
\end{tabular}

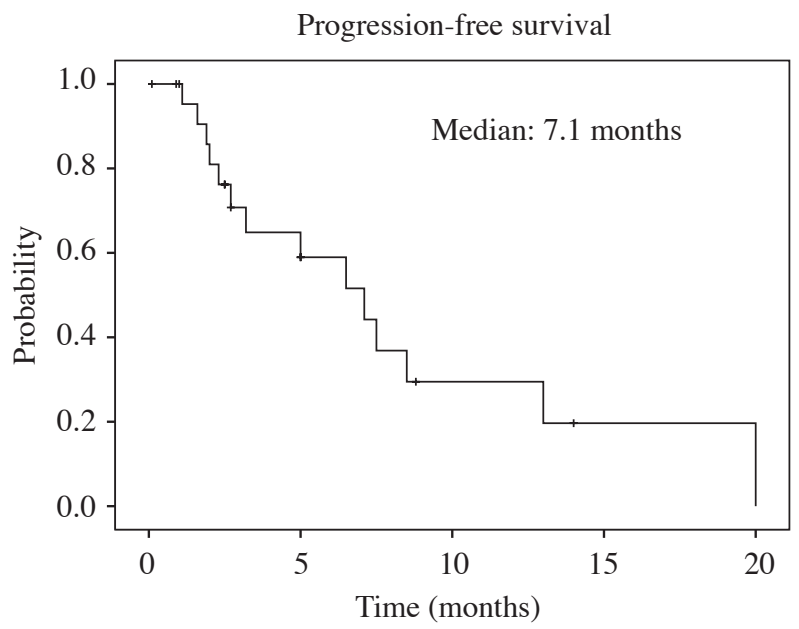

Fig. 1 Kaplan-Meier estimate of progression-free survival (PFS) among 24 patients. The median PFS was 7.1 months (95\% confidence interval, 3.6-10.5 months).

Overall survival

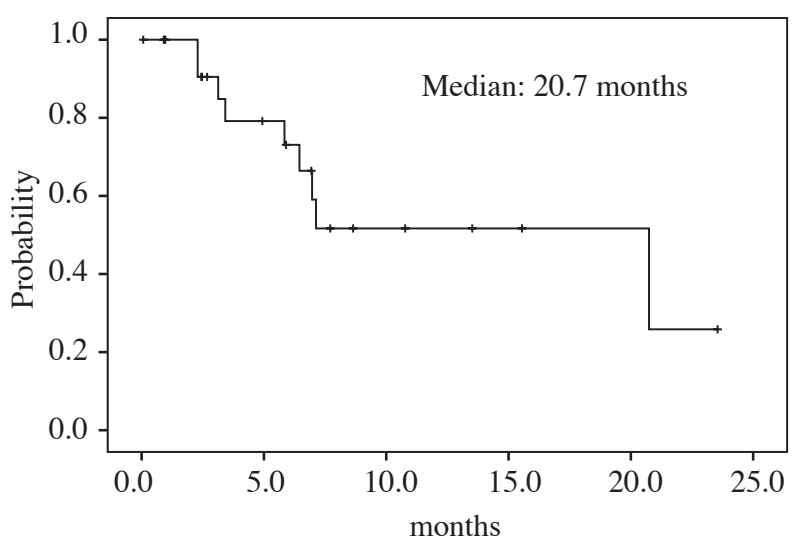

Fig. 2 Kaplan-Meier estimate of overall survival (OS) among 24 patients. There were 9 deaths $(37.5 \%)$ during the follow-up period. The median OS was 20.7 months $(95 \%$ confidence interval, 5.0-36.4 months).
Table 3. Treatment- Related Adverse Events of Interest

\begin{tabular}{lcc}
\hline Events & All grades, No. (\%) & Grades 3/4, No. (\%) \\
\hline Mucositis & $13(54.2 \%)$ & $2(8.3 \%)$ \\
Epistaxis & $4(16.4 \%)$ & 0 \\
Rash & $11(45.8 \%)$ & 0 \\
Pneumonitis & $4(16.4 \%)$ & $2(8.3 \%)$ \\
Anemia & $17(70.8 \%)$ & $6(25 \%)$ \\
Neutropenia & $3(12.5 \%)$ & 0 \\
Thrombocytopenia & $5(20.8 \%)$ & 0 \\
Hypercholesterolemia & $14 / 21(66.7 \%)^{*}$ & $0 / 21$ \\
Hypertriglycemia & $13 / 20(65 \%)^{*}$ & $0 / 20$ \\
Hyperglycemia & $9 / 18(50 \%)^{*}$ & $3 / 18(16.7 \%)^{*}$ \\
Raised AST/ALT & $5(20.5 \%)$ & 0 \\
Raised ALK-P & $6(25 \%)$ & $2(8.3 \%)$ \\
\hline
\end{tabular}

Abbreviations: AST: Aspartate aminotransferase; ALT: Alanine aminotransferase; ALK-P: Alkaline phosphatase; *: Based on cases with available lab data.

these patients, respectively. Fifty percent of the patients with available blood sugar data were diagnosed with hyperglycemia; of these, Grades 3/4 levels were noted in $16.7 \%$ patients.

\section{DISCUSSION}

In the present study, the clinical benefit rate of everolimus treatment following sorafenib and/or sunitinib failure was $62.5 \%$. There was only one patient with a minimal response rather than a partial response. The median PFS and OS after everolimus treatment were 7.1 months and 20.7 months, respectively. The most common non-hematologic toxicities were mucositis, rash and epistaxis.

A Phase III (RECORD-1) trial confirmed the clinical efficacy of everolimus in patients with mRCC who failed initial VERFR-TKI therapy. ${ }^{(8)}$ In the RECORD-1 trial, the partial response rate and clinical benefit rate were $1 \%$ and $68.6 \%$ (190/277), respectively. Recently, the RAD001 Expanded Access Clinical Trial (REACT) in RCC study was primarily designed to evaluate the long- term toxicity of everolimus in a broader and more heterogeneous patient population. ${ }^{(9)}$ The partial response rate and clinical benefit rate in the REACT study were $1.7 \%$ and $53.3 \%$, respectively. In one subgroup analysis of the Japanese population from the RECORD-1 study, the clinical benefit rate was $93.3 \%$ (14/15). However, the result may be vulnerable to the small sample 
size. ${ }^{(10)}$ Our report showed a consistent tumor response in Taiwanese patients.

The median PFS and OS in our study were 7.1 months and 20.7 months, respectively, which were similar to the subgroup analysis of the Japanese population. The longer median PFS and OS in our study compared with the results of the RECORD-1 study may be partly attributed to the better baseline characteristics and longer interval of computed tomography follow-up in our study. Furthermore, the median OS in our study could have been substantially influenced by the length of the follow-up time.

The common adverse events related to everolimus were similar to those reported in the Japanese population from the RECORD-1 trial. ${ }^{(10)}$ Mucositis, rash and epistaxis were the common adverse events, with a frequency of more than $10 \%$. In our study, the overall incidence of non-infectious pneumonitis, a known class effect of rapamycin and its derivatives, was $16.4 \%$. The frequency was similar to that observed in the RECORD-1 study (14\%). ${ }^{(8)}$ Although the frequency of non-infectious pneumonitis in the Japanese population was $27 \%$, all cases were manageable. The majority of adverse events were mild. In the REACT study with a more heterogeneous and broader patient population, everolimus was generally well tolerated without any long-term toxicity. Our findings were consistent with those of the REACT study.

The efficacy of everolimus in patients with RCC with a histology type other than the clear cell type has rarely been addressed. The RECORD-1 study enrolled patients with only the clear cell type. In the REACT study, $5.5 \%$ of the patients had a histology type other than clear cell, however, the response analysis of these patients was not described. ${ }^{(9)}$ In our study, 2 patients had papillary cell carcinoma and 2 had the chromophobe type. Three of these patients achieved disease stabilization as the best response to everolimus treatment, while the other patient could not be followed up long enough to assess the response.

In conclusion, everolimus is consistently effective and safe in Taiwanese patients with $\mathrm{mRCC}$ after failure of VEGFR-TKI therapy. The clinical benefit rate was approximately $62.5 \%$ with a non-inferior median PFS and OS. Toxicity related to everolimus is well tolerated and manageable.

\section{REFERENCES}

1. 2008 Taiwan annual cancer registry report. Available from http://www.bhp.doh.gov.tw/BHPnet/Portal/StatisticsShow.aspx? No=200911300001.Accessed: November 17,2011.

2. Chin AI, Lam JS, Figlin RA, Belldegrun AS. Surveillance strategies for renal cell carcinoma patients following nephrectomy. Rev Urol 2006;8:1-7.

3. Mulders P. Vascular endothelial growth factor and mTOR pathways in renal cell carcinoma: differences and synergies of two targeted mechanisms. BJU Int 2009;104:15859.

4. Hutson TE. Targeted therapies for the treatment of metastatic renal cell carcinoma: clinical evidence. Oncologist 2011;16 Suppl 2:14-22.

5. Eisen HJ, Tuzcu EM, Dorent R, Kobashigawa J, Mancini D, Valantine-von Kaeppler HA, Starling RC, Sorensen K, Hummel M, Lind JM, Abeywickrama KH, Bernhardt P. Everolimus for the prevention of allograft rejection and vasculopathy in cardiac-transplant recipients. N Engl J Med 2003;349:847-58.

6. O'Donnell A, Faivre S, Burris HA 3rd, Rea D, Papadimitrakopoulou V, Shand N, Lane HA, Hazell K, Zoellner U, Kovarik JM, Brock C, Jones S, Raymond E, Judson I. Phase I pharmacokinetic and pharmacodynamic study of the oral mammalian target of rapamycin inhibitor everolimus in patients with advanced solid tumors. J Clin Oncol 2008;26:1588-95.

7. Amato RJ, Jac J, Giessinger S, Saxena S, Willis JP. A phase 2 study with a daily regimen of the oral mTOR inhibitor RAD001 (everolimus) in patients with metastatic clear cell renal cell cancer. Cancer 2009;115:2438-46.

8. Motzer RJ, Escudier B, Oudard S, Hutson TE, Porta C, Bracarda S, Grunwald V, Thompson JA, Figlin RA, Hollaender N, Kay A, Ravaud A. Phase 3 trial of everolimus for metastatic renal cell carcinoma: final results and analysis of prognostic factors. Cancer 2010;116:4256-65.

9. Grunwald V, Karakiewicz PI, Bavbek SE, Miller K, Machiels JP, Lee SH, Larkin J, Bono P, Rha SY, Castellano D, Blank CU, Knox JJ, Hawkins R, Anak O, Rosamilia M, Booth J, Pirotta N, Bodrogi I. An international expanded-access programme of everolimus: Addressing safety and efficacy in patients with metastatic renal cell carcinoma who progress after initial vascular endothelial growth factor receptor-tyrosine kinase inhibitor therapy. Eur J Cancer 2012;48:324-32.

10. Tsukamoto T, Shinohara N, Tsuchiya N, Hamamoto Y, Maruoka M, Fujimoto H, Niwakawa M, Uemura H, Usami M, Terai A, Kanayama HO, Sumiyoshi Y, Eto M, Akaza H. Phase III trial of everolimus in metastatic renal cell carcinoma: subgroup analysis of Japanese patients from RECORD-1. Jpn J Clin Oncol 2011;41:17-24. 


\title{
癌伏妥治療轉移性腎細胞癌的有效性及安全性 一 林口長庚醫院的初期報告
}

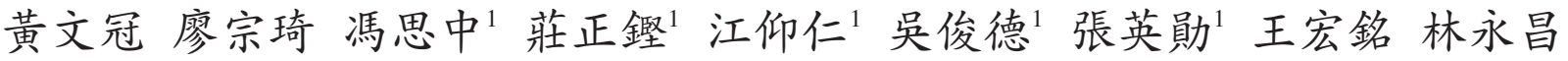 \\ 謝佳娟 歐俐塋 蔡詩怡 楊志勋 ${ }^{2}$ 楊政達 ${ }^{3}$ 張文震
}

背景：癌伏妥已核准做爲以紓癌特或蕾莎瓦治療失敗之轉移性腎細胞癌病患的第二線治療 用藥, 此回溯性研究目的是分析台灣病患使用癌伏妥的有效性及安全性。

方 法：在 2009 年 3 月至 2011 年 8 月期間, 分析 24 位接受癌伏妥治療的轉移性腎細胞癌病 人。在癌伏妥治療之前, 每位病人都接受過至少一種血管内皮生長因子接受器酪胺 酸激酶抑制劑治療。利用 Kaplan-Meier 存活曲線評估無惡化存活期及整體存活期。

結 果： 15 位病人 $(62.5 \%)$ 達到疾病穞定。中位數無惡化存活期爲 7.1 月 (95\% 信賴區間爲 3.6-10.5 月)。中位數整體存活期爲 20.7 月 (95\% 信賴區間爲 5.0-36.4 月)。最常見非 血液方面的毒性爲香膜發炎、皮膚紅疹、流鼻血及非感染性肺炎。

結 論：癌伏妥治療轉移性腎細胞癌的台灣病患是有效的第二線藥物, 副作用是可以忍受且 可以處理的。

(長庚醫誌 2012;35:402-7)

關鍵詞：癌伏妥, mammalian target of rapamycin (mTOR) 抑制劑, 腎細胞癌

長庚醫療財團法人林口長庚紀念醫院血液腫瘤科, 1泌尿科, 2 皮膚科, 3 胸腔內科

受文日期：民國100年11月16日；接受刊載：民國101年2月20日

通訊作者: 張文震醫師, 長庚醫療財團法人林口長庚紀念醫院 血液腫瘤科。桃園縣333龜山郷復興街 5 號。

Tel: (03)3281200轉8825; Fax: (03)3281200轉2362; E-mail: wen1902@ hotmail.com 